\title{
LOS ARTESANOS DE SANTIAGO EN 1850, Y EL DESPERTAR POLITICO DEL SECTOR POPULAR CHILENO
}

\author{
POR \\ CRISTIAN GAZMURI \\ Universidad Católica de Chile. Santiago
}

\section{INTRODUCCIÓN}

El período de la historia de Chile que fue desde 1849 hasta 1851 nos muestra una serie de motines militares y populares, que culminaron en cierta manera en la Guerra Civil de 1851. Esta se dio entre los sectores liberales, en particular de provincias, contra el gobierno conservador que tuvo su principal bastión en la capital, Santiago. La historiografía se ha referido ampliamente a estos episodios. En el trabajo que sigue intentamos enriquecer esa interpretación de la coyuntura. Cuestión que adquiere interés si se observan algunas de las características específicas, y muy marcadas en ciertos casos, que tuvo todo el episodio, como que fue impulsado y protagonizado colectivamente, al menos en su primera fase, por un verdadero club republicano, similar a los franceses de la época de la Monarquía de Julio, la «Sociedad de la Igualdad», la que llegó a reunir unos 3.400 miembros sólo en Santiago, de los cuales quizá unos dos mil artesanos (1), cifra muy considerable en el Chile de entonces. Este aspecto del episodio no ha sido estudiado aún en profundidad. Los historiadores, en especial los conservadores, que han escrito sobre el tema tienden a minimizar la presencia artesanal en el mismo. ¿Fueron

(1) Sobre la cantidad de obreros y artesanos igualitarios, cfr. Benjamín VicUÑa MaCKENNA, Historia de la jornada del 20 de abril de 1851, Rafael Jover, Santiago, 1878, págs. 67, 85, 86 y 153; ver también José ZAPIOLA, La Sociedad de la Igualdad y sus enemigos, Guillermo Miranda, Santiago, 1902 y "La Barra", nos. 69 al 83. Acerca de la cantidad de socios que alcanzó a tener la Sociedad de la Igualdad, la información aparece en un informe publicado por "La Reforma" de Valparaíso con fecha 21 de noviembre de 1850, en relación al proceso contra la Sociedad de la Igualdad a raíz del estado de sitio del 7 de noviembre de 1850 . En el texto queda consignada la existencia de una lista con los nombres de 3.400 miembros. 
realmente los artesanos, unos meros comparsas de un grupo de jóvenes oligarcas liberales intoxicados con el legado ideológico del «48» francés o tuvieron una presencia al menos relativamente autónoma en la coyuntura, la que pueda interpretarse como la primera aparición importante en los sectores populares chilenos en la escena política? Sin pretender dar una respuesta definitiva a esta pregunta el presente trabajo intenta hacer un poco de luz sobre un aspecto que resulta fundamental para solventar la cuestión. Conocer cómo era el mundo artesanal de Santiago de Chile hacia mediados del siglo XIX. Partiendo desde allí podremos deducir cual pudo haber sido su verdadera participación en las revueltas de esos años.

\section{Los aRtesanos de SANTIAgo}

¿Cómo era el mundo artesanal del Santiago de 1850? No existe un estudio completo al respecto. Sin embargo, contamos con la obra de Alberto Romero La Sociedad de la Igualdad que lleva como subtítulo: Los artesanos de Santiago de Chile y sus primeras experiencias políticas 1820-1851(2) obra que no sólo entrega buenos e interesantes datos, sino, además, valiosos elementos interpretativos. Otros autores y testigos de la época nos entregan también conocimientos valiosos, pero se trata de informaciones aisladas.

El trabajo artesanal había existido en Chile desde la Conquista española y tuvo características bastante similares, como institución, a las de las naciones europeas preindustriales. Sólo que había sido, y era todavía hacia la mitad del siglo XIX, por lo general, mucho más tosco y primitivo en sus técnicas. Además, se reducía a la fabricación de artículos de uso diario y doméstico, llegando rara vez a producir objetos refinados y de lujo que requirieran una gran maestría (3). Existían gremios de artesanos estructurados - mutatis mutandis- con las características que tenían estas mismas agrupaciones laborales preindustriales del Viejo Mundo, tradiciones, ritualidades, vinculación religiosa a símbolos y patronos; las más importantes parecen haber sido la

(2) L. Alberto Romero, La Sociedad de la Igualdad, Instituto Torcuato di Tella, Buenos Aires, 1978.

(3) Es la opinión de Romero [2], págs. 12-13, quien la funda en los relatos de memorialistas y viajeros como Samuel Haigh; los objetos que han quedado de aquella épeca confirman este aserto. 
de los sastres (incluyendo los sombrereros), carpinteros, albañiles y mueblistas (4). Existían barrios de artesanos, aunque sin rasgos distintivos acentuados como en el caso europeo. Sarmiento en una serie de artículos publicados en el diario $E l$ progreso en el año 1842, hacía notar que el crecimiento de la ciudad era muy rápido «dejándose percibir fácilmente en la aumentación espontánea de casas, calles, barrios enteros, que antes no existían. Por todos los ángulos de la ciudad se nota esta extraordinaria expansión de la población. Las chimbas se han extendido, las rancherías llamadas huangulies, que hay en todos los suburbios, tiene multitud de casillas y callejuelas, como otros tantos villorios» (5) ¿Dónde estaban o cuáles eran esos villorrios? Al parecer el barrio de Yungay y la zona que se extendía entre la Alameda de las Delicias y el canal de San Miguel cerca de la actual Avenida Mata (6). La actitud política del sector artesanal, siguiendo también el patrón "antiguo régimen», era, salvo las escasas excepciones que veremos, pasiva.

Al parecer, el sector artesanal no se vio mayormente afectado por la apertura comercial consecuencia de la Independencia. La falta de protección tarifaria y el libre ingreso de la producción manufacturera europea, por lo demás todavía muy cara, se vieron compensadas, al parecer por el aumento de la población de las ciudades en un Chile donde todavía no se conocía la industria (7). El hecho es que hacia 1842, Santiago proveía «a la república entera de zapatos, ropa hecha y de mil artículos de consumo diario (8), lo que nos habla de la existencia de un sector artesanal pujante y numeroso, esto lo comprabaremos en el cuadro número 1 .

Lo anterior se explica porque la ciudad de Santiago había crecido aceleradamente después de la coyuntura de la Independencia. Este crecimiento era debido fundamentalmente a la inmigración campesina y tenía raíz económica. La ciudad atraía upor la multitud de modos de vivir que son consiguientes a la

(4) A juzgar por los artesanos que ocuparon cargos directivos en la Sociedad de la Igualdad y el censo de 1854 , que veremos más adelante.

(5) D. F. SARmiento: "Sociedad de Industria y población: Santiago" en El Progreso 22 de diciembre de 1842.

(6) Benjamín Vicuña MackenNa, La transformación de Santiago, Santiago, 1972. Este documento ha sido destacado por A. de Ramón y L. A. Romero en diversos trabajos.

(7) Anibal PInto: Chile un caso de desarrollo frustrado. Ed. Universitaria, Santiago, 1962, pág. 24.

(8) "Santiago", en diario El progreso 19 de diciembre de 1842. Artículo escrito por D. F. Sarmiento, citado por ROMERo, [2], pág. 6. 
complicación (cantidad) de necesidades que hay que satisfacer en ella (9), escribía Sarmiento al respecto en 1842. Agregaba que el inmigrante venido del campo "entrará a la clase del "roto", raso clase receptáculo de todos los que van a hacer el aprendizaje de la vida a Santiago, de allí pasará a tomar uno de los muchos oficios que ha inventado el pueblo para pasar a hacer ayer el día presente que es lo único que lo embaraza. Será "perero", "cirgüelero", "uvero", "duraznero" en verano, "durcero", "velero", "bollero" en invierno... Un día llega a "falte", en cuya profesión y merced a su talento y viveza de su elocuencia, podrá vender por diez lo que cuesta uno y tener el domingo un par de pesos en el bolsillon (10). Pero otros inmigrantes seguían una vía de ascenso social diferente al comercio minorista callejero, se perfeccionaban en algún oficio rudimentario que ya dominaban en sus lugares de origen, por lo común rurales o que aprendían como ayudantes de un "maestro» artesano ya instalado. En 1849 el economista liberal Marcial González, luego de hacer presente la ausencia de industrias en Chile, señalaba «no creo que pueda decirse igual cosa acerca del estado de las artes y oficios manuales. Al mismo tiempo que se ven formarse pueblos (poblaciones) nuevos al lado de los antiguos, mejorarse las construcciones, levantarse en la capital y en provincias templos y edificios públicos ... vemos a la ebanistería, la carrocería, la ferretería, la curtiduría y tantas otras artes cuyo ejercicio era poco conocido, contribuir con sus útiles y perfectas creaciones a la comodidad de nuestras vidas y al progreso y embellecimiento de nuestras jóvenes ciudades (11).

¿Qué porcentaje de la población de Santiago eran artesanos y cómo se desglosaba este universo? El Amigo del Pueblo diario que fue de la Sociedad de la igualdad nos informa de la existencia de 10.000 artesanos en 1850 (12); intentemos el cálculo nosotros. Esto plantea dos problemas: el primero consiste en la necesidad de adoptar un criterio, aunque sea más o menos arbitrario, sobre quienes pueden ser considerados artesanos; en este sentido hemos preferido incluir más bien que excluir, aceptando en la categoría a los trabajadores de todos los oficios que podrían considerarse artesanales 'en cuanto significaban trabajo manual hábil, sin em-

(9) Ibidem.

(10) Domingo F. Sarmiento, en "El Mercurio" de Valparaiso, 3 de abril de 1842, citado por Romero.

(11) Marcial González, "Situación económica del país", en Revista de Santiago, V. I. pág. 36. Citado por Romero [2] González fue protegido del ministro M. C. Vial; su entusiasmo, por lo tanto, debe ser tomado con precaución.

(12) El Amigo del Pueblo, n 14, 16 de abril de 1850. 
pleo de maquinaria compleja y destinado a la producción de bienes; volveremos sobre el punto más adelante. El segundo problema es saber cuántos artesanos existían en la ciudad de Santiago. Esto último nos obliga a hacer algunos cálculos y proyecciones en base a los datos que nos proporciona el censo, complementados con el relativo conocimiento de la época que creemos haber adquirido.

El censo de 1854, documento no demasiado confiable, nos da la cifra de un total de 31.498 artesanos para la provincia de Santiago, además nos proporciona un interesante detalle del número de artesanos por oficios (ver cuadro no 1 ). Siempre tomando como base el citado censo, vemos que el total de habitantes de la provincia de Santiago era de 272.499, de los cuales 142.204 eran adultos (entre los 14 y los 50 años). El Departamento de Santiago, en tanto tenía 129.473 habitantes, de los cuales 72.918 eran adultos. Ahora bien, el Departamento de Santiago comprendía una población mayor que la ciudad de Santiago propiamente tal; ¿cómo llegar a la cifra de los habitantes de ésta? Solo cabe la aproximación. Sumando los habitantes de las cinco parroquias "urbanas» del departamento, tenemos un total de 98.899 personas, de las cuales 57.515 adultos. Pero no todos estos habitantes eran "urbanos" verdaderamente, pues estas parroquias comprendían sectores rurales aledaños a la ciudad. ¿Cuántos eran los habitantes adultos de la ciudad entonces? Hasta el punto en que puede llegarse a partir de los datos del censo sólo podemos saberlo aproximadamente. Richard Morse (13) da la cifra de 85.000 para el año 1845. De ser correcta esa apreciación y tomando las cifras de crecimiento demográfico de la época, podemos presumir que la población santiaguina, ha de ser sido de unos 88.000 habitantes hacia 1850; cantidad que también parece muy plausible a partir del censo. En suma, la población de Santiago en la época que nos interesa bordeaba las 90.000 personas, con algunas pequeñas variaciones estacionales.

Siguiendo la proporción que nos entrega el censo de 1854 de estas 90.000 personas, unas 51.500 habrían sido adultas. ¿Cuántos eran artesanos? Si sabemos que en 1854 existían 31.498 artesanos en la provincia de Santiago para una población adulta de 142.204, vale decir, un $22.1 \%$; siguiendo la misma proporción tenemos que para esa fecha, la cantidad de artesanos de la ciudad sobre 51.500 adultos habría sido de 11.330 y cuatro años antes, en

(13) Richard Morse: Las ciudades latinoamericanas, Sepsetenta, México, 1973, t. II, págs. 29 y ss. 
1850, unos 10.800 , aproximadamente. Sin embargo no podemos tomar esa cifra como valedera. La mayoría de los oficios que vemos en el cuadre $\mathrm{n}^{\mathrm{o}} 1$ son urbanos (notoriamente las 10.011 costureras y 5.454 hilanderas) hechos que debemos complementar con la información que ya tenemos en el sentido que la ciudad de Santiago parece haber sido el centro proveedor de productos artesanales, al menos para toda la zona central de país (ver cita 8). De allí que podemos pensar que la cifra real de artesanos habitantes de Santiago en el año del censo ha de haber sido mayor, quizá de alrededor a 15.000, y hacia 1850 algo menor.

CUADRo 1. ARTESANOS DE LA PROVINCIA DE SANTIAGO POR OFICIOS (14)

\begin{tabular}{|c|c|c|}
\hline OFICIO & HOMBRES & MUJERES \\
\hline Albañiles & 757 & - \\
\hline Alfareros & 19 & 374 \\
\hline Almidoneros & 46 & 18 \\
\hline Amansanderos & 17 & 310 \\
\hline Armeros & 25 & - \\
\hline Artesanos (15) & 102 & - \\
\hline Arregladores de caballos (?) & 95 & - \\
\hline Barberos & 67 & - \\
\hline Bordadoras & 4 & 82 \\
\hline Brocheros & 10 & 1 \\
\hline Caldereros & 28 & - \\
\hline Canteros & 89 & - \\
\hline Carpinteros & 2.094 & - \\
\hline Carroceros & 59 & - \\
\hline Cesteros & 47 & - \\
\hline Cerveceros & 7 & - \\
\hline Cigarreros & 267 & - \\
\hline Coheteros & 10 & - \\
\hline Cordoneros & 11 & - \\
\hline Costureras & - & 10.011 \\
\hline Curtidores & 107 & - \\
\hline Destiladores & 24 & - \\
\hline Doradores & 13 & - \\
\hline Dulceros & 68 & - \\
\hline Ebanistas & 73 & - \\
\hline Empapeladores & 2 & - \\
\hline Encuadernadores & 13 & - \\
\hline Escoberos & 38 & - \\
\hline Escobilleros & 1 & - \\
\hline
\end{tabular}

(14) Si bien hemos incluido todos los oficios que podrían considerarse como artesanales, hay algunos cuya exacta significación no es dudosa. sadas.

(15) Posiblemente se trata de personas de oficios inclasificables o mal cen- 
CUADRO 1. (continuación)

\begin{tabular}{|c|c|c|}
\hline OFICIO & HOMBRES & MUJERES \\
\hline Estereros & 185 & 73 \\
\hline Estriberos & 25 & - \\
\hline Estucadores & 4 & - \\
\hline Fabricantes de cuerdas & 13 & - \\
\hline Fabricantes de fideos & 8 & - \\
\hline Fabricantes de figuras de yeso & 1 & - \\
\hline Fabricantes de chocolate & 21 & - \\
\hline Fabricantes de pianos & 7 & - \\
\hline Fabricantes de tejas y ladrillos & 93 & - \\
\hline Fabricantes de paño (16) & 1 & - \\
\hline Fundidores & 8 & - \\
\hline Grabadores & 4 & - \\
\hline Guitarreros & 18 & - \\
\hline Herradores & 72 & - \\
\hline Herreros & 711 & - \\
\hline Hilanderas & 39 & 5.454 \\
\hline Hojalateros & 61 & - \\
\hline Hojeros & 2 & 37 \\
\hline Hormilleros & 7 & - \\
\hline Jaboneros & 42 & - \\
\hline Joyeros & 35 & - \\
\hline Lamparistas & 11 & - \\
\hline Mantequilleros (17) & 4 & - \\
\hline Marmolistas & 7 & - \\
\hline Matanceros & 126 & - \\
\hline Mecánicos & 8 & - \\
\hline Miriñaqueras & - & 124 \\
\hline Modistas & - & 22 \\
\hline Molineros & 156 & - \\
\hline Panaderos & 483 & 113 \\
\hline Paragüeros & 8 & - \\
\hline Pasteleros (18) & 4 & 3 \\
\hline Peineros (fabricantes de peines) & 44 & 1 \\
\hline Peluqueros & 28 & - \\
\hline Pelloneros (fabricantes de pellones) & 174 & 17 \\
\hline Pescadores & 157 & - \\
\hline Petaqueros & 99 & - \\
\hline Pintores de edificios & 154 & - \\
\hline
\end{tabular}

(16) Fabricantes de paño no significaba, evidentemente fabricantes de tela; los o las fabricantes de telas han de haber estado incluidos/as entre los hilanderos y tejedores.

(17) El mismo caso de la nota 16. Resulta difícil concebir que en la provincia de Santiago hubiesen sólo cuatro fabricantes de mantequilla. Posiblemente están incluidos entre los queseros y lecheros, que en cuanto "comerciantes" no hemos incluido entre los artesanos.

(18) Pasteleros estaban también incluidos probablemente entre los "dulceros" y quizá "panaderos". 
Cuadro 1. (continuación)

\begin{tabular}{|c|c|c|}
\hline OFICIO & HOMBRES & MUJERES \\
\hline Pintores de historia & 16 & - \\
\hline Plateros & 117 & - \\
\hline Plumeros & 6 & 1 \\
\hline Queseros & 6 & 29 \\
\hline Relojeros & 20 & - \\
\hline Rienderos (fabricantes de riendas) & 106 & 7 \\
\hline Salineros & 1 & - \\
\hline Sangradores & 10 & - \\
\hline Sastres & 862 & - \\
\hline Silleteros & 68 & 1 \\
\hline Sombreros & 109 & 7 \\
\hline Talabarteros & 238 & - \\
\hline Tapiceros & 60 & 20 \\
\hline Tejedoras & 47 & 1.730 \\
\hline Tintoreros & 17 & 27 \\
\hline Tipógrafos & 83 & - \\
\hline Toneleros & 59 & - \\
\hline Torneros & 9 & - \\
\hline Vacunadores & 3 & - \\
\hline Vasijeros & 7 & - \\
\hline Veleros & 79 & 1 \\
\hline Vidrieros (19) & 1 & - \\
\hline Volantineros (fabricantes de volantines) & 3 & - \\
\hline Zapateros & 3.881 & 313 \\
\hline TOTAL & 12.722 & 18.776 \\
\hline
\end{tabular}

TOTAL ABSOLUTO: $31.776(20)$

Por el cuadro $\mathrm{n}^{\mathrm{Q}} 1$ no nos permite apreciar el peso político del mundo artesanal chileno de la época. Siguiendo la tendencia del censo tendríamos que sólo un 40,5 \% de esos artesanos habrían sido varones; y sólo varones son los artesanos que hemos encontrado interviniendo en lo que podríamos llamar el "48" chileno, en particular como miembros de la Sociedad de la Igualdad. Esto es perfectamente comprensible dentro del ambiente cultural de la época, donde la mujer no sólo no tenía derechos políticos

(19) Llama también, en un primer momento, la atención que en toda la provincia de Santiago figurase sólo un fabricante de vidrio; pero, por otra parte, sabemos Zapiola [1], que el vidrio de ventaja sólo se vino a imponer por esa época o algo después. Es posible presumir que esos primeros vidrios de venta eran importados.

(20) Censo de 1854, Imp. del Ferrocarril, Santiago, 1858. 
sino que se veía postergada en casi todo orden de cosas; por otra parte no deja de ser sugerente que mientras los hombres copaban casi todo el abanico de posibilidades artesanales, las mujeres artesanas fuesen en su inmensa mayoría o costureras, hilanderas o tejedoras, oficios ligados al ámbito doméstico. Un 40,5\% de 15.000 es 6.075; esa cifra, o una algo mayor, correspondía, aproximadamente, al total de los artesanos adultos varones de la ciudad de Santiago alrededor de 1850. Estos habrían sido los participantes "potenciales" en las conmociones políticas revolucionarias de esos años. Como dijimos más arriba, la Sociedad de la Igualdad pudo haber contado con la simpatía de hasta unos dos mil de esos artesanos, vale decir jun tercio! de ese universo potencial.

Esto resulta sorprendente. El mundo artesanal había estado hasta entonces marginado del mundo político, al menos formal. Durante la época colonial había existido una organización gremial ligada a formas de sociabilidad de tipo religioso (cofradías, etc.). Su presencia política, dentro del sistema colonial, prácticamente no existía. Con el advenimiento de la República esto parece no haber cambiado (21). A diferencia de Europa, donde fueron los antiguos gremios medievales la base de las asociaciones obreras modernas (22), en Chile esto parece no haber ocurrido.

Antes del período que nos interesa ("el 48" chileno o lo que sea) la forma de expresar el descontento de los sectores artesanales ante determinadas situaciones se confundían con las de la muchedumbre urbana en general, incluyendo por cierto a los sectores marginales, "rotos», trabajadores esporádicos o de simple fuerza muscular, lumpen y vagabundos. Esta forma era el motín. Los historiadores nos cuentan de varios motines en Santiago y Valparaíso durante las décadas de 1830 y 1840. El fenómeno tenía mucho de estallido de ira insconsciente contra un orden y un sistema que no sentían propio ni entendian, pero frente al cual sólo reaccionaban ante agresiones evidentes y puntuales: algún exceso de autoridad especialmente brutal o situaciones ambiguas que alteraban la rutina de la diaria convivencia. El primer motín de Chile independiente del que tenemos noticia (17 de abril de 1818), tuvo un cierto carácter político y se dio en apoyo del guerrillero Manuel Rodríguez y contra el recientemente formado gobierno de Bernardo O'Higgins. Recordemos que Ro-

(21) Guillermo Feliú C.: Santiago a comienzos del siglo XIX, Ed. Andrés Bello, Santiago 1970.

(22) André Jardin y A. Tudeso, La France des notables (1815-1848). Eds. de Sevil, Paris 1973, pág. 221. 
dríguez se había transformado durante las guerras de la Independencia en una figura mítica en los ambientes populares (23).

Pero el motín protagonizado por el elemento popular urbano durante las primeras décadas de la República solía no tener motivación política explícita; un ejemplo de motín en cuanto expresión de descontento soterrado de características verdaderamente curiosas, pero además interesantes para comprender la mentalidad del pueblo santiaguino de la época, se dio en mayo de 1839. Barros Arana nos cuenta que por esos días «llegó a Santiago un "aeronauta" norteamericano que anunció que se elevaría en un gran globo en un lugar público donde pudiera cobrar una entrada... La autoridad local fijó para ello la plaza principal... El espectáculo era tan nuevo en Chile que la plaza se llenó de gente de todas las condiciones y en especial de plebe... El globo pendía en medio de la plaza de unos aparatos de madera y cerca de ellos había unos barriles llenos de gas que debían inflar el globo y producir su elevación. Apenas se habían iniciado los trabajos preparatorios, el aeronauta anunció que no podía efectuarse la ascensión porque el globo tenía una pequeña rotura... Aunque se anunció al público que todo individuo al retirarse de la plaza recibiría los dos reales que había pagado, la plebe creyó que todo aquello no era más que una desvergozada estafa. Su primer impulso fue echarse sobre el aeronauta, sobre el globo y sobre los demás aparatos y destrozarlo todo. Intervino la polícia. El aeronauta fue llevado a la cárcel para ponerlo a salvo de la plebe. Pero ésta, más y más indignada, cargó violentamente contra la policía. La plaza había sido empedrada tres o cuatro años antes con piedras del río y ese pavimento suministró a los insurrectos un arma que sabían manejar con singular maestría. Hicieron caer, en efecto, una verdadera lluvia de piedras sobre los policías, derribaron algunos de los caballos que montaban y obligaron a los otros a retroceder".

«La plebe quedó entonces dueña de la plaza. Todas las puertas que caían sobre ésta, la de la Casa de Gobierno, la de la residencia del Presidente (etc., etc.) estaban perfectamente cerradas. En la Plaza se oía una desordenada gritería y comenzaban a partir piedras sobre las ventanas. Mientras tanto desde las habitaciones del Presidente se avisó, por el interior, al cuartel general de bomberos. Había allí un escuadrón de caballería de unos 150 a 180 hombres. Salieron estos apresuradamente montados en bue-

(23) Marcelo SEgAL: "Las luchas de clase en las primeras décadas de la República", separata de Anales de la Universidad de Chile, Santiago, 1962, pág. 2. 
nos caballos, sable en mano, y cayendo como un rayo sobre la plebe, repartían golpes a diestra y siniestra... antes de oscurecer todo había entrado en orden; y los heridos que habían quedado por el suelo porque no podían huir, eran recogidos y transportados al hospital» (24).

En la década de 1840, hubieron varios motines políticos en que participaron artesanos. Uno, con clara intención de ese tipo, se dio en 1844 con motivo de la condena impuesta a Francisco Bilbao (entonces de 21 años) con motivo de la aparición de su libro Sociabilidad chilena. Terminado el proceso «Bilbao fue recibido como un verdadero triunfador, en medio de los aplausos y vítores de una concurrencia de millares de personas en la que, si bien dominaban por su número los estudiantes, se encontraban muchos hombres de pueblo de la clase de los artesanos» (25).

En Santiago y en Valparaíso, en 1846, hubo motines de carácter político con motivo de las elecciones presidenciales de ese año. Después de lo ocurrido en Santiago fueron apresados varios dirigentes Pipiolos (liberales), entre ellos Pedro Félix Vicuña, dos parientes y Rafael Bilbao. En ambos hubo violencia, en el de Valparaíso fueron muertos por parte del ejército ventidós miembros del «populacho» (26).

En cuanto a huelgas, las primeras ocurridas en Chile se dieron en la década de 1830 entre los mineros de la región de Copiapó; las que, por cierto, estaban insertas en un contexto social y laboral muy diferente al que nos preocupa (27). La primera huelga ocurrida en Santiago hasta donde sabemos, se dio precisamente por esos años (1849) entre los empleados de sastrerías. Refiriéndose a ésta escribía Sarmiento: «Estamos muy lejos de considerar este asunto como una lucha de clases, como una disidencia entre el rico y el pobre, ni como la aparición entre nosotros de las perturbaciones que agitan hoy a otras sociedades... Lo que por ahora nos interesa, es que los artesanos, maestros y oficiales, conozcan las leyes que sigue el salario en su alta y su baja, a fin de que unos y otros no se crean atacados en sus

(24) Diego Barros Arana: Un decenio de historia de Chile, Impr. Barcelona, Santiago, 1913, tomo I, págs. 96-97.

(25) Ibíd., t. I, pág. 532.

(26) "El Mercurio" de Valparaíso de los días 9 y 30 de marzo de 1846 informa sobre ambos motines.

(27) Con respecto a las huelgas mineras de Copiapó en la década de 1830 y 1840, ver: Roberto HERNÁNDEZ C.: Juan Godoy o el descubrimiento de Chañarcillo, citado por. H. RAmírez: Historia del movimiento obrero en Chile, Ed. L. A. R. Santiago, 1986, pág. 133. 
derechos». El asunto debía ser tratado «en los términos más simples ... contrayendo la cuestión (sólo a la pugna) entre los maestros y oficiales de sastrerías". Sarmiento se empeñaba en imponer la idea que el asunto era una simple cuestión de salario y a un exceso de oferta de trabajo, en especial por parte de las mujeres que trabajaban "con igual perfección por la mitad del salario" (28). Pero ese empeño del analista demuestra más bien su preocupación de que el asunto tuviera alcances más generales y -ergo- la existencia de un clima de intranquilidad en el artesanado. Otras informaciones de la época confirman los problemas y la intranquilidad del mundo laboral santiaguino de entonces y la imposibilidad en que se veían en mejorar su situación usando de los mecanismos que ponía a su disposición la institucionalidad. Romero menciona varias protestas y peticiones de sectores artesanales a las autoridades (29). Los pocos fragmentos de discursos pronunciados por jefes artesanos de la Sociedad de la Igualdad que se han conservado, destacan las desigualdades económicas y la miseria material a que estaban condenados; lo que revela que existía un grado de conciencia sobre los mismos. Pero, a pesar de estos brotes de rebeldía, la capacidad de acción política, oposición al sistema y lucha por sus reivindicaciones de los artesanos del Chile de la primera mitad del siglo XIX parece haber sido mínima.

En cuanto a organizaciones, ya vimos que las cofradías gremiales de la Colonia se prolongaron durante la temprana república. Con todo, existieron algunas organizaciones de artesanos de tipo moderno antes de 1850 , pero éstas parecen haber sido instrumentos de los sectores políticos oligárquicos en sus pugnas y su acción fue esporádica y coyuntural. En 1829, un tipógrafo de apellido Laynes organizó una agrupación política de artesanos en apoyo de Portales y los Pelucones (conservadores); pero duró poco; después del triunfo militar de este bando en Lircary fue disuelta por la fuerza y Laynes debidamente encarcelado (30). Otra, de más pretensiones, fue organizada en 1845. Barros Arana nos da noticia de ésta, mostrándonos que también fue un instrumento en manos de la oligarquía, aunque del bando Pipiolo esta vez: «No fue difícil reunir algunas decenas de artesanos en una asociación a la cual se dio el pomposo nombre de "Sociedad

(28) D. E. SARmiento, El Salario, aparecido en La Crónica, 25 de febrero de 1849; citado por ROMERO [2].

(29) ROMERo [2], pág. 11.

(30) SEgaL: [23], pág. 9. 
Caupolicán". Se puso a su cabeza a don Manuel Guerrero y Prado, joven de ventajosa posición social por sus relaciones de familia y por su educación"... Aquella asociación tenía por propósito el filantrópico pensamiento de sacar el sufragio de la afrentosa cadena que lo encadenaba y envilecía... El «Diario de Santiago", al dar la noticia de la instalación de la sociedad anunciaba que ésta tenía ya más de trescientos afiliados, lo que era una enorme exageración. El número de asociados, o más bien de concurrentes a la sociedad no alcanzaba a sesenta (31). Tenemos también noticia de la existencia de otras agrupaciones hacia la misma época (32), pero la escasez de información confiable es tal que se puede presumir que estas fueron también grupos de muy poca importancia. Sin embargo, incluso la existencia de estas débiles asociaciones nos indica que hacia medio siglo, existía una conciencia político-social emergente en el mundo artesanal.

\section{LOS ARTESANOS EUROPEOS EN CHILE}

La inmigración de artesanos europeos parece haber sido uno de los factores de agitación del artesanado santiaguino hacia 1850. Esta inmigración era bien vista, más todavía, promoverla constituía una de las preocupaciones de los hombres públicos de la época. Sarmiento dedicó una serie de artículos al tema en el diario La Crónica el año 1849. Pero los artesanos inmigrantes no sólo traían nuevas técnicas, sino también nuevas ideas - ya veremos que la fundación de la escuela de Artes y Oficios en 1849, causó "problemas»- no debemos olvidar que los inmigrados, en particular los llegados después y quizá a raíz del "48" desde los países donde esas revoluciones fueron más radicales y violentas, eran personas que probablemente tenían una conciencia política y social desarrollada.

Esta es otra cuestión sobre la cual aporta importante información el censo de 1854. En el cuadro 2 aparecen las cifras relativas a los artesanos europeos procedentes de esos países que habitaban en Chile; es probable que buena parte de estos artesanos llegaran después de 1848, cuando en las naciones que mencionamos en dicho cuadro se desató la represión contra los revolucionarios inicialmente triunfantes.

(31) Barros [24], págs. 79-81.

(32) El Pueblo, 25 de enero de 1846. 
CUADro 2. ARTESANOS EXTRANJEROS INMIGRANTES A CHILE DESDE PAISES EUROPEOS DONDE HUBO MOVIMIENTOS REVOLUCIONARIOS IMPORTANTES EN 1848

\begin{tabular}{ll}
\hline OFICIO & PAIS \\
\hline
\end{tabular}

Alema-

nia(33) Austria Francia Hungria Irlanda Italia Prusia Suiza

\begin{tabular}{|c|c|c|c|c|c|c|c|c|}
\hline Albañiles & 7 & - & 4 & - & 1 & 1 & - & - \\
\hline Alfareros & 2 & - & 2 & - & - & - & - & - \\
\hline Armeros & 1 & - & 2 & - & - & 1 & - & - \\
\hline Artesanos (?) & 5 & - & 4 & - & - & - & - & - \\
\hline Arregladores de caballos & - & - & 1 & - & - & - & - & - \\
\hline Calafateadores' (34) & 1 & - & 1 & - & - & 1 & - & - \\
\hline Caldereros & 2 & - & 8 & - & - & - & - & - \\
\hline Canteros & - & - & - & - & - & - & - & - \\
\hline Carpinteros & 147 & 1 & 97 & 1 & 2 & 16 & 6 & 4 \\
\hline Carroceros & - & - & - & - & - & - & 1 & - \\
\hline Costureras & 一 & - & - & - & 1 & - & - & - \\
\hline Fabricantes de fideos & - & - & - & - & - & 8 & - & - \\
\hline Fabricantes de pianos & 7 & - & - & 一 & - & - & - & 一 \\
\hline Fabricantes de paño & - & - & 2 & - & - & - & - & - \\
\hline Fabricantes de sacos & 1 & - & - & - & - & - & - & - \\
\hline Fundidores & 一 & - & 5 & - & 1 & 1 & - & - \\
\hline Grabadores & 2 & - & - & - & - & - & - & - \\
\hline Herreros (35) & 26 & - & 50 & - & 1 & 6 & 1 & - \\
\hline Hilanderas & - & - & 1 & - & - & - & - & - \\
\hline Hojalateros & 3 & - & 8 & - & - & - & - & - \\
\hline Jaboneros & 7 & - & 2 & - & - & - & - & - \\
\hline Joyeros & 8 & - & 14 & - & - & 3 & 1 & - \\
\hline Lamparistas & 1 & - & 1 & - & - & - & - & - \\
\hline Marmolistas & 1 & - & 3 & - & - & - & - & - \\
\hline Maquinistas & 14 & - & 13 & - & - & - & - & - \\
\hline Matanceros & 3 & - & - & - & - & - & - & - \\
\hline Mecánicos & 8 & - & 11 & - & - & 1 & - & - \\
\hline Modistas & 6 & - & 36 & - & - & - & - & - \\
\hline Molineros & 15 & - & 25 & - & 1 & 6 & - & - \\
\hline Panaderos & 27 & - & 33 & - & 1 & 4 & 1 & - \\
\hline Paragüeros & - & - & 2 & - & - & 1 & - & - \\
\hline Pasteleros & - & - & 6 & - & - & 1 & - & 1 \\
\hline Peluqueres & - & - & 16 & - & 1 & - & 一 & - \\
\hline Pescadores & - & - & 1 & - & - & 6 & - & - \\
\hline Pintores de edificios & 3 & - & 19 & - & 1 & 5 & - & 1 \\
\hline Pintores de historia & 1 & - & 3 & - & - & 1 & - & - \\
\hline
\end{tabular}

(33) Excepto Prusia.

(34) * Oficios que no figuran en el cuadro $n^{0} 1$.

(35) Herreros no eran sólo los fabricantes de herraduras. También se consideraba herreros a los forjadores. 
Alema.

nia Austria Francia Hungria Irlanda Italia Prusia Suiza

Plateros

Queseros

Relojeros

Sastres

Silleteros

Sombrereros

Talabarteros

Tapiceros

Tejedores

Tintoreros

Tipógrafos

Toneleros

- Torneros

Veleros (36)

Zapateros

\begin{tabular}{rrrrrrrr}
- & - & - & - & - & - & 1 & - \\
6 & - & - & - & 1 & - & - & - \\
16 & 1 & 38 & - & - & - & - & 5 \\
- & - & - & - & - & 1 & - & - \\
3 & - & 9 & - & - & - & 1 & - \\
8 & - & 6 & - & - & - & - & - \\
14 & - & 8 & - & - & - & - & - \\
5 & - & - & - & - & - & - & - \\
1 & - & 6 & - & - & - & - & - \\
1 & - & 1 & - & - & 1 & - & - \\
16 & - & 17 & - & - & - & 2 & - \\
5 & - & - & - & - & 1 & 1 & - \\
1 & - & 11 & - & - & - & - & - \\
17 & - & 22 & - & - & 1 & - & - \\
397 & 2 & 492 & 1 & 11 & 68 & 16 & 14 \\
\hline
\end{tabular}

TOTAL ABSOLUTO 1.001

Ahora bien, ¿cuántos de estos 1.001 artesanos se establecieron en Santiago? No nos los indica el censo, aunque sí nos entrega la cifra total de nacionales de los países referidos en el Cuadro 2 establecidos en esta ciudad en 1854. Estos extranjeros eran 763 de los cuales 563 varones. Presumimos que en su mayoría eran adultos, pues el inmigrante generalmente llegaba soltero o al menos sólo (37) y sus hijos nacían en Chile con la calidad de chilenos. También presumimos que de estos 763 europeos nativos de naciones donde existió un fuerte "espíritu de 48" una buena cantidad eran artesanos. No lo sabemos con certeza, pero nuestra

(36) Fabricantes de velas para alumbrado.

(37) Ver bibliografías de europeos llegados a establecerse en Chile en: $\mathbf{N}$. VeGA: Albím de la colonie française au Chili, Santiago, 1903 y La inmigración europea en Chile 1882-1895, Santiago, 1896; Benjamín Vicuña MaCkENNA: "Los franceses en Chile, un siglo bajo la Colonia y bajo la República 1770-1830", en "El Mercurio" de Valparaíso 4 y 9 de mayo de 7 de junio de 1883; también J. P. BlanCPAN: Francia y los franceses en Chile. Hachette, Santiago, 1987. El inmigrante europeo decimonónico viajaba, por lo común, soltero, o al menos, sólo inicialmente. 
idea que estos han de haber representado una proporción apreciable parte de la base que Santiago era el lugar en Chile donde había mayor demanda de bienes de lujo, de servicios sofisticados y del trabajo de técnicos, lo que hacía necesaria la presencia de trabajadores especializados: sastres, carpinteros (probablemente mueblistas), joyeros, herreros, forjadores, relojeros, maquinistas, etc. Oficios en que la proporción de extranjeros era la más alta (comparar cifras de cuadros 1 y 2).

Cabe hacer notar que de los inmigrantes alemanes la mayoría (quizá la gran mayoría) de ellos han de haber llegado a las provincias del extremo sur del Chile, zona de inmigración germana de la época. De éstos, al parecer una proporción significativa, eran artesanos aunque no parece que fuesen de ideas muy progresistas. Blancpain afirma: "a una inmigración de burgueses acomodados atraídos por los ofrecimientos tentadores de Renous y Kindermann, sucede [por la época que nos interesa] una corriente irregular y difícil de campesinos acomodados y artesanos". Pero no deja de hacer presente que prohombres como M. A. Torcornal, convencidos (en 1849) del triunfo de las ideas socialistas en Europa se mostraron dispuestos a aceptar la inmigración de artesanos aunque de ideas "contrarias" a esa corriente (38).

¿Influyeron estos artesanos europeos sobre la conciencia, el imaginario y la conducta social y política de sus colegas chilenos? Creemos que es algo muy probable. Un caso concreto parece haberse producido con motivo de la fundación, en 1849, de la Escuela de Artes y Oficios; para la cual se trajeron desde Europa "maestros de taller» siendo nombrado director Jules Jaries, antiguo subdirector de la Escuela de Artes y Oficios de Angers. La Escuela de Artes y Oficios de Santiago estaba destinada a formar jóvenes artesanos chilenos de alto nivel técnico; sin embargo, a poco de su fundación "se suscitaron dificultades con algunos maestros de taller venidos del extranjero, a quienes fue preciso separar, lo que fue causa de perturbación" (39). ¿Qué tipo de dificultades se suscitaron? No hemos encontrado información al respecto; pero más que incompetencia profesional que habría impedido su contrato, nos inclinamos a creer en problemas políticos derivados de sus ideas.

(38) P. Blancpain: Los alemanes en Chile, Hachette, Santiago, 1965, págs. 53

(39) BARRos [24], pág. 419. 


\section{EL IMAGINARIO SOCIAL Y POLÍTICO DE LOS ARTESANOS DE SANTIAGO HACIA 1850}

En la década de 1840 se publicaron en Santiago algunos diarios de corta vida, afines a los intereses de los sectores populares; Barros Arana menciona dos El Duende y El Pueblo aparecidos en 1845 y 1846 durante la agitación política que se dio durante la elección presidencial (40). El tono de estos impresos era violento y a veces abiertamente revolucionario; en "El Pueblo", editado por el tipógrafo Santiago Ramos ("El Quebradino») se hacía una fuerte denuncia de la condición social política y económica del artesano al «que se le había llevado como vil esclavo a sufragar por la voluntad del Gobierno». Proclamaba que el artesano "convenido de su poder" podía llegar a gobernar; pero el tono era ético y retórico, los métodos que proponía eran pacíficos y se proclamaba «liberal» y dedicó varias ediciones a publicar una larga declaración de principios llamada «Diadema Ministerial» que era una cerrada defensa el ideario político dieciochesco (41). Sin embargo, no por esto dejó de reproducir un manifiesto titulado "Cartilla Republicana" inspirado en el socialismo utópico, - posiblemente en Louis Blanc a juzgar por el lenguaje utilizado- (42). Sin embargo resulta arriesgado pensar que había entre los artesanos de la época un grupo de discípulos de Blanc u otro pensador socialista; "El Pueblo» era un diario de trinchera, del tipo que aparecía con motivo de las campañas electorales financiado por alguno de los sectores políticos oligárquicos en contienda, para la obtención de una meta de corto plazo. En este caso parece haber sido un instrumento al servicio de los pipiolos, pues en el número 5 reclama contra la prisión de varios integrantes de este sector, entre ellos Rafael Bilbao.

Por otra parte, El Mercurio de Valparaíso del 24 de febrero de 1846 daba una furibunda respuesta a un artículo aparecido en el periódico La Gaceta dos días antes, firmado por "un falso

(40) Ibid, t. II, págs. 89 y ss.

(41) El Pueblo, 25 de enero, 3, 14 y 22 de febrero de 1846 (nos. 2, 3,5 y 6).

(42) "La 'Asociación' es la forma necesaria"; "Al estado 1, le toca tomar la iniciativa en las reformas industriales que sean capaces de producir una organización del trabajo", etc. Recordemos que Louis Blanc fue el dirigente socialista más importante, los años previos al "48"; que después fundó los "Talleres Nacionales", propiedad del estado y que uno de sus libros más conocidos se titulaba precisamente La organización del trabajo (París, 1840). 
artesano" y el ejemplar del 2 de abril del mismo año reprodujo una arenga titulada "A los Artesanos". De la lectura de ambos escritos queda en evidencia que el principal de los instigadores de la agitación «obrera» era el pipiolo Pedro Félix Vicuña. En elecciones anteriores ya había existido estas publicaciones incendiarias, las que morían junto con el ambiente electorero.

¿Fue el discurso artesanal de los motines de los años 1850 y 1851 sustancialmente diferente, reflejo de un imaginario renovado? En 1850, los discursos pronunciados por los artesanos que fueron dirigentes de la Sociedad de la Igualdad tendían a destacar, en lo político, los valores republicanos, la igualdad, las libertades individuales $y$, en general, el ideario político-social republicano, liberal e igualitario con origen en la Revolución Francesa; en lo económico propiciaban la nivelación dentro de un régimen de propiedad privada - recordemos que se trataba de artesanos y no proletarios-; en lo social destacaban la necesidad de unidad y de lucha contra la pobreza y los vicios, recogiendo así el mensaje mesiánico del carácter ético, tan típico del socialismo utópico y del catolicismo social a lo Lamennais. No hacía alusión a la situación de otros grupos sociales postergados, notoriamente los campesinos. En suma, se trataba de un discurso más bien abstracto que -en un nivel más bajo de racionalidad- no era muy diferente de los dirigentes de origen oligárquico de la Sociedad de la Igualdad (43). No debemos olvidar que los dirigentes artesanales aludidos habían estado en contacto permanente con Santiago Arcos, Francisco Bilbao recién llegados de París y otros jóvenes Pipiolos, y que muchas de las ideas que expresaron han de haberlas recibido de éstos. Pero también sabemos por Barros Arana que había artesanos que se distinguían por «su ficción a la lectura de diarios", por "cierto tinte de ilustración" (44). En esa medida, su imaginario sin duda había incorporado algunas de las ideas-fuerza del "48" europeo, sobre el cual la prensa informaban ampliamente. Recordemos que cuando se recibió en Santiago la noticia de la caída de Luis Felipe de Orleans y la instauración de la Segunda República francesa, se produjo una explosión de júbilo. En carta fechada en mayor de ese año, Leoncio Levraud, Cónsul General de Francia en Chile, informaba al Quai D'Orsay del enorme entusiasmo reinante: "Esta tarde - escribía Levrauden el teatro, la compañía italiana y los espectadores cantaron el

(43) La Barra: nos 129, 143, 148 (noviembre de 1850 y enero de 1851).

(44) BarRos [24], t. II, pág. 383. 
Himno Nacional y La Marsellesa»; no dejando de agregar, sin embargo, que una parte de la aristocracia "parece aterrorizada. Se teme un acercamiento entre la franca práctica de los principios de la Francia republicana y las pretendidas libertades de Chile, que no son más que mentira y burla» (45). En todo caso el entusiasmo era mayoritario y Levraud recibió incluso la visita del venerable Andrés Bello - quien difícilmente podría ser catalogado de revolucionario- que acudió personalmente a felicitarlo.

El republicano Chile - tomando en serio su condición de talse felicitaba por la instauración de la república en la admirada Francia, los periódicos abundaban en elogios. El Mercurio de Valparaíso, en un artículo aparecido el 30 de mayo de 1848 afirmaba: "oponerse al torrente sería suicidarse. No hay barreras para las ideas y sobre todo para las ideas generosas proclamadas por los hombres sinceros de la Francia»; el 5 de junio decía: "la revolución francesa de 1848, hecha en el interés de la humanidad, conducida para la ilustración y sancionada por la religión, traerán a Chile la verdadera libertad y aunque se hagan los más inauditos esfuerzos para contener este espíritu y este sentimiento que germinando en la tierra hace tanto tiempo, nace hoy con una lozanía y vigor, que nada puede oponerse a su desarollo». El 9 de junio, en un arranque de euforia, se hacía eco, al menos parcial, de la opinión de aquellos días en el sentido "que nada nos trae de nuevo la Revolución Francesa en ejemplo y en principios, porque todo lo que ella ha proclamado existía ya en Chile desde hace 37 años». Más todavía, en la Memoria del Departamento de Relaciones Exteriores al Congreso Nacional, firmada por el ministro Manuel Camilo Vial, se expresaba que «El gobierno de Chile ha visto con una viva satisfacción" lo sucedido en Francia (46). Sin embargo, la verdadera faz republicana del Chile de entonces, según la concebía el gobierno pelucón, la Iglesia Católica, y, en general, los sectores conservadores de la oligarquía, quedó en evidencia, cuando, a los pocos días, también comenzaron a aparecer las prevenciones y críticas a la marcha de los sucesos en Francia. Varios meses después, en cuanto se supo el de la revolución proletaria de junio en París, el discurso contra-

(45) Jorge Edwards, "El decenio de Bulnes a través de los archivos del Quai D'Orsay", en Boletin de la Academia Chilena de la Historia, $\mathrm{n}^{\mathrm{9}} 74$, Santiago, pág. 20.

(46) "El Mercurio" de Valparaíso, 30 de mayo, 4 a 9 de junio de 1848; la Memoria ministerial, en: El Araucano, 13 de octubre de 1848. 
rrevolucionario se manifestó con toda virulencia (47). Los años siguientes esta descalificación absoluta del «48» francés y europeo continuaría. Pero el entusiasmo por las revoluciones del «48» se mantuvo entre la juventud pipiola y, suponemos, entre el artesanado más informado y consciente, que quizá ya comenzaba a estar influido además por inmigración revolucionaria europea llegada a Chile como consecuencia del «48».

\section{CONCLUSIÓN}

En suma, existen indicios que, aunque aislados y poco concluyentes, hacen presumir que hacia mediados del siglo XIX la cultura del artesanado chileno o, al menos sus elementos más conscientes, habían comenzado a derivar hacia la aceptación de los elementos centrales del ideario político de la modernidad. En esa medida su oposición hacia el autoritarismo conservador que caracterizaba al gobierno del Chile de esa época pudo tener raíces mucho más genuinas y fuertes que lo pensado hasta hoy, por mucho que el agente precipitador de la nueva conducta hubiese sido exógeno. Si así fue, los motines de 1850 habrían marcado el despertar político de los sectores populares chilenos.

(47) Ignacio MuÑoz Délano: "Análisis cuantitativo de la evolución del imaginario del sector aglutinado en torno a la revista Católica" en: Nuestra Epoca, Santiago, sept. 1989, págs. 22-40. La Tribuna, el diario pelucón que representaba el pensamiento del grupo que rodeaba a M. Montt, muestra también la revolución descrita en el texto. Otro interesante testimonio acerca la euforia que despertó en Chile la revolución francesa de 1848 y la reacción del gobierno pelucón es el del francés Joseph Miran en: Un Français au Chili. Editions du C.N.R.S., París, 1987, págs. 49-50. 